\title{
Lançando anzóis: uma análise cognitiva de processos mentais em tradução
}

\author{
Fábio Alves da Silva Jr. \\ Universidade Federal de Minas Gerais
}

\begin{abstract}
The search for a general concept which would explain concisely the nature of the translation process has been an ongoing theme within the field of Translation Theory. Lately, this search has pondered on the nature of translation both as a product and a process and produced several attempts towards such a concept. However, all of these attempts have remained, at their best, at a classificatory level. Trying to fill this conceptual gap, this article criticizes the applicability of concepts such as equivalence and adequacy within the field of Translation Theory and, then, drawing on Sperber \& Wilson (1986), it offers a complementary view, based on Relevance Theory, which amalgamates both Shannon and Weaver's (1949) Code Model and Grice's (1957) Inferential Model. The theoretical discussion is illustrated with empirical material collected by means of thinking-aloud protocols from German/ Portuguese translations.
\end{abstract}




\section{INTRODUÇĀO}

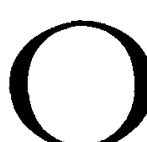

s esforços humanos no âmbito da comunicação interlingual e intercultural têm sido no decorrer da história objeto de reflexão por parte de diferentes autores. No que diz respeito à tradução, existem na área acadêmica várias obras e artigos que comprovam que a tarefa de tradução representa um processo muito especial. A Ciência da Tradução produziu, principalmente nas últimas três décadas, inúmeros trabalhos que, de pontos de vista diferentes, muitas vezes antagônicos, procuram explicar e esclarecer a análise de textos de partida e de chegada e o processo de tradução. Neste artigo, concentro-me, sobretudo, no desenvolvimento da abordagem lingüística em tradução no decorrer das últimas três décadas e sobre suas possíveis conseqüências no âmbito da discussão a que me proponho. ${ }^{1}$ Em língua alemã, a discussão acadêmica chegou mesmo a gerar o termo Übersetzungswissenschaft Ciência da Tradução - em sua busca de autonomia para os estudos tradutórios. Considerações epistemológicas permitem-nos observar, porém, que a assim chamada Ciência da Tradução procura, ainda hoje, fundamentar o seu objeto de estudo e os instrumentos necessários para explicar seus passos, procurando um conceito geral que consiga definir de forma clara e concisa o processo tradutório e lançar as bases de uma Teoria Geral da Tradução. Este artigo procura contribuir para essa discussão, examinando a evolução conceitual na área de tradução à luz de uma abordagem psicolingüística.

\section{A DICOTOMIA PRODUTO vs PROCESSO}

Nos últimos anos, a procura por um conceito geral para a Teoria da Tradução mencionada acima gerou uma diferenciação 
teórica do objeto de estudo, vendo-se a tradução seja como produto - i.e.: a análise textual dos textos de chegada - seja como processo. - i.e.: a análise cognitiva dos processos mentais subjacentes ao ato de traduzir. Enquanto o estudo da tradução como produto tem como objeto de estudo sobretudo o texto de chegada, ou seja, um produto final, o estudo da tradução como processo prioriza a análise das etapas de processamento mental que, juntas, vêm a constituir o processo tradutório. Diferencia-se, assim, a tradução - associada ao produto - do traduzir - associado ao processo. ${ }^{2}$

Dando ênfase ao estudo do processo tradutório, priorizo aqui uma abordagem teórica dentro do que Königs (1990) define epistemologicamente, para a área de tradução, como Teorias de Primeira Ordem (Theorien erster Ordnung), em contraposição às assim chamadas Teorias de Segunda e Terceira Ordens. São definidas como Teorias de Primeira Ordem:

"aquelas teorias que se ocupam concretamente do objeto de tradução observado, ou de parte dele, abrangendo o maior número possível de variáveis pertinentes a esse objeto. Elas se formam de maneira indutiva e são sobretudo descritivas, e em casos excepcionais também prescritivas. São fundamentadas empiricamente e contribuem decididamente para o esclarecimento sobre a formação de um produto específico." (Königs 1990:111, tradução do autor)

As chamadas Teorias de Primeira Ordem opõem-se às Teorias de Segunda e Terceira Ordens que são definidas abaixo:

"Teorias de Segunda Ordem ocupam-se de um objeto de estudo autoconcebido - e não de um objeto de estudo produzido por um outro sujeito. Encontram-se focalizadas sobre o formulador da teoria e sua experiência pessoal, sendo basicamente dedutivas, sobretudo prescritivas e somente em parte capazes de explicar a formação de um produto específico. Não são comprovadas empiricamente e não apresentam provas de validade intersubjetiva. Por sua vez, as Teorias de Terceira Ordem surgem através da comparação de produtos sob aspectos não pertinentes à tradução, sendo 
essencialmente descritivas, incapazes de explicações, isolando apenas um dos muitos aspectos de uma tradução." (Königs 1990:111, tradução do autor)

$\mathrm{Na}$ área de pesquisas em tradução, são exemplos de Teorias de Segunda Ordem os trabalhos de orientação lingüistica de Albrecht (1973), Catford (1965) e Diller \& Kornelius (1978). Sendo sobretudo dedutivos e prescritivos, eles permanecem sobre o nível do produto, examinando a tradução apenas através de seus resultados. Os trabalhos de orientação de análise textual de Thiel (1981) e Nord (1980) são também exemplos de Teorias de Segunda Ordem, pois partem de uma perspectiva dedutiva ao desenvolverem um modelo de análise textual com cuja ajuda o texto de partida é 'seccionado' em suas características textuais, permitindo que o texto de chegada seja controlado, verificando-se se esse contém os mesmos elementos textuais de sua contrapartida. A validade intersubjetiva dos modelos apresentados é apenas postulada, faltando-lhes comprovação empírica. Dentro dessa mesma linha de raciocínio, classificam-se os trabalhos de orientação contrastiva de Vinay \& Darbelnet (1958), Truffaut (1983) ou Newmark (1988) como Teorias de Segunda e Terceira Ordem. Aqui as equivalências entre estruturas lingüísticas das línguas de partida e de chegada são contrastadas, listadas e sistematizadas, resultando na apresentação de interessante material criativo, sem contudo oferecer uma explicação para o seu surgimento - como no caso da Stylistique Comparée - ou direcionadas à experiência pessoal do autor, funcionando prescritivamente como nos casos dos trabalhos de Truffaut (1983) e Newmark (1988).

São exemplos de Teorias de Primeira Ordem na área de tradução os trabalhos de orientação funcional de Hönig \& Kußmaul (1982) e Reiß \& Vermeer (1984). Através da Skopostheorie, Reiß e Vermeer trabalham indutiva e dedutivamente, levam em consideração o maior número possível de variáveis no decorrer do processo tradutório e procuram ligar o resultado de uma tradução à sua função. É interessante, porém, ressaltar que esse tipo de abordagem teórica necessita de maior comprovação empírica, sem a qual corre-se o 
risco de que a discussão teórica permaneça em nível meramente especulativo (cf. Lörscher 1988:80).

Dando ênfase ao processo tradutório, a abordagem psicolingüística em tradução é também uma abordagem baseada em Teorias de Primeira Ordem desenvolvida entre outros por Königs (1987), Krings (1986), Ségu inot (1989), Lörscher (1991) e Bell (1991). Ela visa à análise cognitiva de processos mentais em tradução, trabalhando indutiva e descritivamente, sempre através de embasamento empírico, contribuindo decididamente para o esclarecimento do como e do porquê da criação de um determinado produto: o texto de chegada de uma tradução. Dentro da abordagem psicolingüística, a análise textual em tradução - $\mathbf{a}$ análise do produto de uma tradução - não é rejeitada. Ela passa apenas a ser vista como mais um elemento de contribuição ao escopo total do objeto de estudo da área de tradução que, ao se ocupar do estudo da tradução e do traduzir, inclui a análise do produto de uma tradução dentro do escopo maior da análise do processo tradutório.

\section{UMA ABORDAGEM PSICOLINGÜÍSTICA DO PROCESSO TRADUTÓRIO}

Como objeto de pesquisa, o processamento mental em tradução já foi investigado empiricamente tanto de maneira estritamente psicolingüística (cf. Königs (1987), Krings (1986)) quanto, mais recentemente, através de uma abordagem que incorpora à psicolingüística componentes transculturais (cf. Alves 1995). Fica claro, através desses trabalhos, que a análise de processos cognitivos leva a um aperfeiçoamento qualitativo dos aspectos didáticometodológicos da tradução. A diferenciação entre a tradução/ produto e o traduzir/processo é o ponto de partida para esse aperfeiçoamento.

A partir dos conceitos de $A d b o c-B l o c k$ e Rest-Block (cf. Königs 1987), abriu-se espaço para o acompanhamento do processo tradutório dentro de uma abordagem psicolingüística. No $A d b o c-B l o c k$ 
- o bloco adhoc - trabalham-se, na maioria das vezes inconscientemente, ${ }^{3}$ processos mentais já automatizados. Sob sua influência, o tradutor chega a equivalências previamente estabelecidas e, geralmente, não mais as modifica. Pesquisas empíricas (cf. Königs 1987) confirmam que, uma vez que decisões tradutórias tenham sido tomadas, processamentos mentais no bloco adhoc têm grande resistência a mudanças pelo mesmo tradutor.

Um exemplo do próprio Königs (1987) parte da semelhança entre os itens lexicais el cura e la cura do espanhol e de sua tradução para o alemão. Um de seus informantes tinha automatizado a tradução do espanhol para o alemão de el cura como der Pfarrer - o padre - e, apesar de não encontrar uma solução contextual satisfatória para o texto que traduzia, insistia em sua tradução sem perceber que a diferença entre os artigos masculino e feminino na palavra espanhola gerava um outro item lexical que lhe era desconhecido. ${ }^{4}$ Somente quando o informante atenta para essa diferença é que surge a possibilidade de trabalhar o item lexical la cura, que lhe era desconhecido, em uma nova fase de processamento mental: o bloco restante.

No bloco restante, por sua vez, ocorrem as partes do processo tradutório para as quais não existe ainda uma tradução automatizada, espontânea ou interiorizada por parte do tradutor. As estratégias e técnicas de tradução encontram aqui sua aplicação direta. Um passo nessa direção foi dado com a introdução de um modelo do processo tradutório por Bell (1991). Paralelamente ao modelo de Bell e expandindo o modelo de Königs, proponho aqui o desenvolvimento de uma abordagem psicolingüistica em tradução, voltada para as Ciências Cognitivas, utilizando a metáfora do computador ${ }^{5}$ para explicar as diversas etapas de processamento mental observadas ao longo do processo tradutório. Examinam-se processamentos em mémorias de curto e longo prazo, a recuperação de memória previamente armazenada, estratégias e processos inferenciais utilizados na solução de problemas, processos de tomada de decisão, operações mentais em série e em paralelo. Aborda-se, assim, o 
processo tradutório de maneira análoga aos processamentos cognitivos sugeridos por Searle (1990), encontrando-se paralelos entre a Ciência da Tradução e as Ciências Cognitivas. O objeto de estudo da tradução passa a acompanhar as evoluções teóricas do desenvolvimento recente na área de Ciências Cognitivas. Através de uma abordagem coneccionista (cf. Anderson 1991), o processamento mental simbólico em série deixa de ser a única modalidade a ser considerada. A ela acrescenta-se também uma modalidade de processamento mental em paralelo responsável pela ocorrência simultânea de várias atividades conscientes e inconscientes. Observando-se o desempenho do tradutor durante o exercício do ato de traduzir, estabelece-se uma ponte natural entre cognição e processos de aprendizado.

\section{RELEVÂNCIA: O PROCESSO TRADUTÓRIO E A PRAGMÁTICA}

Para ilustrar o desenvolvimento desse processo, parte-se inicialmente de dois modelos de processamento de informações distintos: o modelo de código de Shannon \& Weaver (1949) e o modelo inferencial de Grice (1975). O modelo de código explica, através do fluxo de informações entre emissor e receptor, o princípio básico para a troca de mensagens em qualquer processo de comunicação, e foi o ponto de partida para a comunicação informática. Contudo, o modelo de código negligencia a questão semântica. O problema do sentido e da ambigüidade na troca de informações no clecorrer de processos comunicativos é ignorado. Essa é exatamente a preocupação de Grice (1975) que, em seu artigo Logic and conversation, cria as condições necessárias para o surgimento da pragmática dentro da lingüística contemporânea. Contudo, o modelo inferencial de Grice espera de ambos, emissor e receptor, um grau de cooperação mútua a fim de que o processo comunicativo seja otimizado. O princípio cooperativo e as máximas de Grice qualidade (verdade e eviclência); quantidade (concisão); modo. 
(clareza e evitar ambigüidade) e relevância - falham, porém, na explicação de certos processos tradutórios, nos quais a cooperação entre autor e tradutor é inexistente e impossível. Toma-se por exemplo a frase alemã:

(1) Die MS Kemnade, ein schmuckes, weißes Fahrgastschiff.

(O MS Kemnade, um barco de passageiros enfeitado e branco) ${ }^{6}$

Na sua tradução para o português tanto continental quanto brasileiro, esse sintagma nominal foi traduzido por alguns informantes a partir das seguintes verbalizações:

(2) O MS Kemnade, um agradável barco de passeio branco. Não, não gosto! Eu vou tirar o branco. O barco vai ficar incolor. Não faz mal. Não fica bem!

(3) Algumas coisas eu tiro fora, sabe... Um bonito branco navio... Não sei. Eu achei que teria que pôr outra forma. Tirei o branco. Eu tiraria o bonito talvez também.

(4) Tem ao seu dispor um lindo barco. Um bonito, pois, um bonito. Lindo é melhor que bonito. Tem um lindo. Tem ao seu dispor um lindo barco de passageiros. Branco. Eu aqui não vou pôr branco. Que não dá!

(5) Um schmuckes, weißes Fahrgastschiff... Aqui dá pra fazer uma aliteração que eu gosto. Um bonito barco branco. Eu gosto! Um bonito barco branco.

Observa-se que o princípio cooperativo de Grice entre as intenções do emissor e do receptor inexiste nas verbalizações acima. O emissor, o departamento de turismo da cidade de Bochum tem, através de um comportamento dito ostensivo, o objetivo de divulgar um texto publicitário ressaltando as possibilidades de entretenimento aquático na cidade. Os receptores, por sua vez, trabalham o SN a partir de um comportamento dito inferencial, limitado pela abrangência de seus respectivos ambientes cognitivos, sem mesmo conhecer maiores detalhes da cidade em questão. Trata-se de um processo de comunicação assimétrico em que o tradutor decide 
sozinho, por exemplo, pela retirada ou manutenção de um item lexical específico - weiß (branco) - no texto de chegada.

Para superar esse problema com o princípio cooperativo de Grice, proponho, para a área de tradução, a utilização do conceito pragmático de Releváncia como ele é apresentado e defendido por Sperber \& Wilson (1986) e utilizado por Gutt (1991) e por Alves (1995), desenvolvendo e fornecendo instrumentos epistemológicos para o aprimoramento da análise cognitiva de processos mentais em tradução. Isso remete-nos agora ao título desse artigo: Lançando anzóis. O que se procura fazer, à luz da teoria de Relevância e apoiado pela noção epistemológica de Teorias de Primeira Ordem em tradução, é reconstruir as várias etapas de processamento cognitivo no decorrer de um número finito de traduções e ampliálas na reprodução de um modelo abrangente que busca descrever, em forma de fluxo, todos os passos possíveis entre a escolha de uma unidade de tradução em um dado texto de partida e sua conversão em uma decisão de tradução em um texto de chegada. Defendo a idéia de que essas etapas são processadas na forma de anzóis cognitivos, com o auxílio dos quais o tradutor desloca-se em meio a unidades de tradução entre os textos de chegada e de partida, instrumentalizando-se para tomar decisões tradutórias.

Ao proporem um amálgama do modelo de código de Shannon \& Weaver (1949) e do modelo inferencial de Grice (1975), Sperber \& Wilson (1986) definem Relevância, dentro de processos comunicativos, como uma característica de processamento mental, que tem como objetivo a melhor contextualização com o menor esforço possível, através de um comportamento ostensivo por parte do emissor e por um comportamento inferencial por parte do receptor, apoiados por manifestação mútua dentro de um dado ambiente cognitivo. Alcança-se através dessa interação um efeito contextual, ${ }^{7}$ resultado da interação entre informações novas e velhas. Relevância, é, em suma, o resultado desse efeito contextual.

Esta análise de processos comunicativos diferencia-se dos princípios e máximas de Grice principalmente por não haver aqui 
necessidade de um alto grau de cooperação entre o emissor e o receptor.

Uma comparação pode ser agora proposta. Enquanto o modelo inferencial de Grice parte do princípio de que

"a comunicação deve ter um objetivo comum ou um conjunto de objetivos ou, pelo menos, uma direção aceita mutuamente." (Grice 1975: 45, apud Sperber \& Wilson 1986: 161, tradu ção do autor),

espera-se da comunicação, em uma perspectiva que trabalha com o conceito de Relevância, apenas "uma relação entre uma suposição e um contexto." (op.cit.:125)

A literatura em pragmática explica a seqüência de eventos comunicativos geralmente através da seguinte ordem de acontecimentos: o contexto é determinado, ocorre um processo de interpretação e a noção de relevância é avaliada. Desta forma, a noção de relevância é determinada somente após a ocorrência de mecanismos de processamento mental associados à contextualização e à interpretação de novas informações. Este é geralmente o conceito mais corrente de relevância.

Parto, porém, do princípio de que o conceito de Releváncia, como ele é definido por Sperber \& Wilson (1986), oferece uma explicação mais adequada para o desenrolar de processos mentais, principalmente no que diz respeito ao desenrolar de processos mentais no decorrer do processo tradutório (cf. Alves 1995). Relevância deixa de ser vista apenas como o resultado da aplicação de mecanismos inferenciais. Ela passa a ser considerada como uma característica do processamento mental que permite a contextualização mais adequada possível no decorrer de processos comunicativos. Relevância não estabelece previamente qualquer ênfase semântica de determinadas características lingüísticas. Funcionando paralelamente ao desenrolar de processos cognitivos, ela tanto direciona as decisões de escolhas semânticas para informações novas quanto orienta a utilização de informações velhas. Para o processo tradutório, Relevância é, em suma, a característica de processamento 
mental através da qual uma determinada unidade de tradução é contextualizada em um dado texto de chegada, sempre sob a observação de subfatores como adequação e equivalência (alguns exemplos de traduções de SNs do alemão para o português serão apresentados na próxima seção).

\section{POR UM CONCEITO GERAL PARA A TEORIA DE TRADUÇĀO}

Para esclarecer com mais detalhes o porquê da argumentação feita acima, gostaria de avançar mais, através do exame de uma progressão conceitual verificada ao longo dos últimos trinta anos na área de pesquisas em tradução. A Ciência da Tradução tem procurado um conceito geral que permita explicar tanto o produto quanto o processo tradutório de maneira simples e concisa. Inicialmente trabalhou-se com o conceito de equivalência. Esse conceito foi tido por Catford (1965) como tertium comparationis, foi dividido entre equivalência formal e dinâmica por Nida (1975), classificado como equivalência cognitiva por Newmark (1988) e como comunicativa por Neubert (1988) e pela escola de Leipzig. Como conceito, equivalência tem efeito sobretudo no nível do sintagma e da sentença e, ao longo do desenvolvimento de procedimentos de análise textual, também sobre o nível do texto, procurando sempre a correspondência mais próxima entre o texto de partida e de chegada. $O$ conceito de equivalência, embora abrangente, restringese, porém, ao nível do produto, não levando em consideração as etapas intermediárias do processo tradutório e limita-se, dentro de minha definição anterior, ao campo de Teorias de Segunda Ordem.

Posteriormente, House (1977) diferenciou entre overt e covert translation. Como covert translations são classificadas as traduções que não são reconhecidas como tais no texto e língua de chegada. Overt translations, por outro lado, são aquelas traduções que se mantêm próximas às características do texto de partida e se orientam em função da língua de partida. Trabalha-se aqui literalidade em 
oposição a funcionalidade. Dando seqüência à discussão teórica, um novo conceito proposto por Reiß \& Vermeer (1984), dentro da Skopostheorie, contradiz o conceito de equivalência como conceito geral da Ciência da Tradução. Em seu lugar, propõe-se que uma ação é determinada por seu objetivo e é, dentro dessa perspectiva, uma função desse objetivo. Trata-se de uma tentativa de formulação de uma Teoria de Primeira Ordem na qual nenhum aspecto do texto original tem, impreterivelmente, que fazer parte do texto de chegada. Dentro da Skopostheorie existe uma série de objetivos que podem ser classificados hierarquicamente. Um novo conceito, chamado por Reiß \& Vermeer de adequação, (Adäquatbeit), não chega, contudo, a preencher plenamente a função de conceito geral para a ciência de tradução. Concordo com a crítica, feita por Gutt (1991), de que, apesar de levar em consideração etapas processuais, a Skopostheorie e o conceito geral de adequação, assim como o conceito de equivalência que critica, mantêm a mesma falha conceitual anterior através de uma nova classificação, dessa vez de características hierárquicas dentro dos objetivos de tradução.

$\mathrm{Na}$ busca de um conceito geral para a teoria de tradução, faço aqui a sugestão de que o conceito de Relevância seja examinado à luz do trabalho de Gutt (1991) em sua especificidade epistemológica para a área de tradução e que sua análise seja contrastada com o modelo de análise cognitiva apresentado em Alves (1995), e que, dentro de seus aspectos cognitivos, essa análise seja contraposta às idéias de Fodor (1983); Maturana \& Varela (1988); Posner (1989); Searle (1990, 1992); Dennett (1991) e Varela et al. (1991).

Dentro dos limites do presente trabalho, e apenas para fins ilustrativos, introduzo abaixo quatro SNs, combinações de adjetivos e substantivos em alemão, a serem traduzidos para o português: ${ }^{8}$

(6) Klirrender Frost (geada tilintante);

(7) Stattliche Wettkampfmaße (competições imponentes);

(8) Freie Babn (raia livre);

(9) Brausende Gischt (espuma efervescente). 
Dentro das considerações epistemológicas definidas acima, observa-se que, entre todos os 24 informantes consultados em Alves (1995), o SN foi separado em núcleo e complemento, ou seja, substantivo e adjetivo. O substantivo foi traduzido inicialmente e a ele acrescentada a tradução literal do adjetivo correspondente. $E$ É interessante observar que, no nível de processamento mental, os 24 informantes buscaram, para chegar a um produto final, equivalência e funcionalidade. No nível processual, contudo, sua busca é direcionada por um outro fator, subjacente ao produto almejado, ou seja, todos os 24 informantes buscaram um efeito contextual relevante para tomarem suas decisões cle tradução. Os exemplos abaixo ilustram esse processo:

Para o SN alemão stattliche Wettkampfmaße:

(10) Stattlich, stattliche Wettkampfmaße..., ..., ... Wettkampfmaße já são duas palavras... E onde é que se há de colocar o adjetivo? Tem que se dizer que a maior parte das piscinas tem, penso, acredito, que as dimensões de competições não soa muito bem... Sei mais ou menos o que quer dizer.

(11) A maioria das piscinas tem consideráveis medidas de competição. Não, impressionantes. Vou tirar isso e colocar simplesmente, a maioria das piscinas tem dimensões olímpicas. É a mesma coisa. Acho que até melhor em português.

Para o SN alemão freie Babn:

(12) Por exemplo, freie Bahn, tanto pode ser uma expressão, como pode ser uma trajetória livre, e eu optei pela trajetória livre. Que eu achei melhor aqui no caso.

(13) E depois eu não entendi direito esse freie Bahn aqui. A primeira idéia que eu tinha tido era de transporte gratuito, não sei o quê, para as pessoas que estavam indo par as piscinas. Na hora que eu li pela primeira vez. Depois eu já fiquei achando que eram pistas livres, pistas de corrida mesmo. Aí depois, terceira possibilidade, já fiquei achando que era mais ligado à natação mesmo. Fiquei na dúvida ainda se era, que aqui não falava direito se era pra nadar ou se era... Se era pra correr. 
Para o SN alemão klirrender Frost:

(14) Como é que o Frost pode ser klirrend em português? Um klirrender Frost...

(15) Caso a geada tilintante? Isso não se diz. A expressão equivalente pra klirrender Frost em português é frio de rachar.

(16) Fica primeiro o gelo e depois o adjetivo. O gelo klirrend. Ai meu Deus! Não gosto! Em Portugal não há gelo. Não sei como se caracteriza o gelo. Acho que o gelo vai ficar por caracterizar agora durante uns tempos. $\mathrm{O}$ gelo...

Para o SN alemão brausende Gischt:

(17) In der brausenden Gischt... Brausend? Brausende? ... ... Brausenden Gischt... Quem sabe com o Gischt eu arrumo um sentido pra brausend...

(18) Brausende Limonade eu sabia, mas brausend... /// É um purgante... Brausend... ... Que as espumas murmurantes...

(19) Bramante, impetuoso, ruidoso, estridente, estrondoso. $\mathrm{Na}$ espuma, envolvido pela espuma estridente? Estrondosa? Ruidosa? Não! Brausend... Efervescente. Pela efervescente espuma.

Apesar da busca por aspectos equivalentes e funcionais para as unidades de tradução apresentadas em (6)/(9), não são essas as características condutoras do processo tradutório verbalizadas em (10)/(19). Em um nível mais profundo, o tradutor busca uma representação semântica e a partir dela dá início ao processo tradutório buscando uma forma proposicional na língua de chegada que tenha a mesma semelhança representativa que a forma proposicional da língua de partida. É somente após ter encontrado esta semelhança representativa que o tradutor consegue tomar uma decisão de tradução que pode, então, vir a ser trabalhada em nível de produto, levando-se em conta as características funcionais e os critérios de equivalência váliclos para a tradução em questão.

À luz do conceito de Releváncia, o processo tradutório passa a ser explicado concisamente de acordo com o modelo a seguir: 


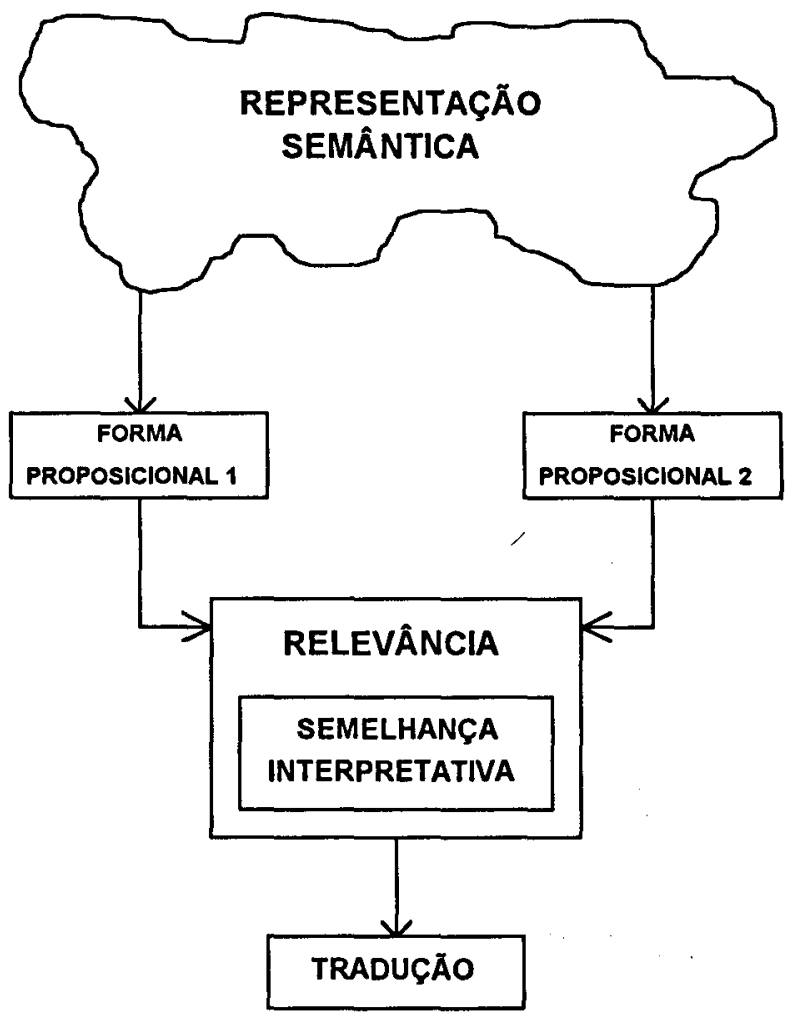

FIGURA 1

Retomo aqui a análise feita acima com o SN alemão:

(1) Die MS Kemnade, ein schmuckes, weißes Fahrgastschiff

As verbalizações (2)/(5) ilustram que, de formas diferentes, os informantes tomaram a decisão de traduzir o SN (1) após haverem encontrado uma semelhança representativa entre a forma proposicional 1 em alemão e uma determinada forma proposicional 2 em português, entre inúmeras outras possibilidades. Essa forma proposicional 2 gera em português um efeito contextual subjetivo 
semelhante à representação semântica da qual a forma proposicional $1 \mathrm{em}$ alemão havia se originado. A representacão semântica tem caráter simbólico e deve ser expressa através de uma forma proposicional que representa, no nível lógico-analítico da língua, a sua estrutura profunda.

A decisão tradutória explica-se, então, não pela busca de equivalentes funcionais ou pela definição de objetivos hierárquicos, mas sim pela noção de semelhança interpretativa. Partindo do princípio de que as diferentes unidades de um dado texto de partida são representações mentais que se dividem em representações semânticas e formas proposicionais, o processo tradutório é caracterizado como a busca mental de uma semelhança interpretativa para uma dada representação semântica através de duas formas proposicionais - uma na língua de chegada e outra na língua de partida. Essas duas formas proposicionais dividem entre si uma semelhança interpretativa. A decisão tradutória ocorre quando o tradutor, dentro de suas características individuais de proficiência lingüística e experiência profissional, 'toma a decisão mental' de ter encontrado, não no nível de funcionalidade ou de objetivos hierárquicos, mas em um nível mais profundo, a semelhança interpretativa de duas formas proposicionais oriundas de uma mesma representação semântica. Explicamse, assim, decisões antagônicas como (2) e (5), nas quais o adjetivo alemão weiß- branco - é rejeitado em (2) e mantido em (5) no texto de chegada em português, como decisões idênticas no nível processual resultantes da aplicação da mesma forma de processamento mental: o conceito de Relevância.

Observemos novamente os exemplos citados anteriormente em (6)/(9). Que semelhançàs processuais encontramos entre as verbalizações de súas traduções em (10)/(19)?

Em todas elas, antes que os fatores equivalentes ou funcionais fossem considerados, ocorreu uma troca de informações novas e velhas, contrapondo uma mesma representação semântica a uma série de possíveis formas proposicionais. As formas 'um lindo barco de passeio' e 'um bonito barco branco' para Die MS Kemnade, ein 
scbmuckes, weißes Fabrgastschiff, 'piscina gratuita' e 'pista livre' para Freie Babn, 'geada tilintante' e 'um frio de rachar' para klirrender Frost ou 'espumas murmurantes' e 'efervescentes espumas' para brausende Gischt são passíveis de crítica no nível da análise qualitativa do produto final de uma tradução, o texto de chegada. No nível processual, todas elas espelham, porém, a mesma característica de processamento mental. São formas proposicionais obtidas a partir do efeito contextual gerado sobre uma determinada representação semântica.

\section{CONCLUSĀO}

A partir das discussões teóricas nas duas áreas citadas acima - Ciências Cognitivas e Ciência da.Tradução -, complementa-se o quadro teórico aqui proposto visando ao estudo de tradução centrado na inter-relação entre cognição e processos de aprendizagem de língua estrangeira.

Dentro da área das Ciências Cognitivas, esses passos encontram eco tanto no modelo de esboços múltiplos - multiple draft model - de Dennett (1991), quanto na introdução do conceito emergente de cognição proposto por Francisco Varela (1991) como complementar às perspectivas cognitivistas e coneccionistas, mais tradicionais dentro de uma abordagem fenomenológica. Gostaria de deixar claro que vejo essa linha de pesquisa em tradução como um campo ainda não totalmente definido. Como vimos nas verbalizações acima, os informantes mostram que o processo de tradução encontra-se em estado de constante transformação sem levar jamais a um produto final estático. $O$ processo tradutório não tem fim, operando sempre de forma recursiva e cíclica, podendo ser interrompido, paralisado ou finalizado através de uma decisão consciente do tradutor. O conceito de Relevância e a noção de semelhança interpretativa parecem-me explicar, no presente momento, com relativa clareza e de forma concisa, as diversas etapas de um processo mental 
requintado e de extrema complexidade. Espero, também, que os anzóis aqui lançados possam servir de estímulo no futuro para novas reflexões e possíveis contribuições para o aperfeiçoamento de pesquisas de orientação psicolingüística na área de tradução.

\section{NOTAS}

${ }^{1}$ Não se leva em conta neste artigo uma abordagem especificamente literária de estudos tradutórios. Para discussões sobre o encontro, algumas vezes controverso, entre a lingüística e a teoria da literatura no campo da tradução, remeto o leitor a Königs (1990) e Snell-Hornby (1988).

${ }^{2}$ Cf. Bell 1991 para os termos translation e translating.

${ }^{3}$ Nào se trata aqui do conceito freudiano de inconsciente que permanece potencialmente acessível à percepção consciente. São aqui considerados como atos inconscientes apenas aqueles oriundos de características neurofisiológicas da espécie humana, incapazes de serem acessados e processados conscientemente (cf. Searle 1990, 1992).

${ }^{4}$ Documentado em Alves (1995).

${ }^{5}$ Remeto o leitor a Maturana \& Varela (1988) para uma discussão sobre o uso da metáfora do computador no âmbito das Ciências Cognitivas.

${ }^{6}$ Atente-se para o fato de que essa é apenas uma entre inúmeras possibilidades de tradução desse $\mathrm{SN}$ do alemào para o português.

7 Para uma melhor compreensão dos conceitos em itálico - comportamento ostensivo-inferencial, manifestação mútua, ambiente cognitivo e efeito contextual - centrais na elaboração do conceito de Relevância, remeto o leitor à leitura da obra de Sperber \& Wilson (1986).

${ }^{8}$ Atente-se, novamente, para o fato de que essa é apenas uma entre inúmeras possibilidades de tradução desse $\mathrm{SN}$ do alemão para o português.

\section{REFERÊNCIAS BIBLIOGRÁFICAS}

ALBRECHT, J. Linguistik und Übersetzung. Tübingen, 1973.

ALVES, F. Zwischen Schweigen und Sprechen: Wie bildet sich eine transkulturelle Brücke? - eine psycholinguistisch orientierte Untersuchung von Ubersetzungsvorgängen zwischen portugiesischen und brasilianischen Übersetzern. Hamburg, 1995. 
ANDERSON, J.A. Comments on Foundations of Cognitive Science. Psychological Science 2/5, 1991, p. 283-287.

BELL, R.T. Translation and Translating, Theory and Practice. London, 1991.

CATFORD, J.C. A Linguistic Theory of Translation: An Essay in Applied Linguistics. London, 1965.

DENNETT, D. Consciousness Explained. London, 1991.

DILLER, H.-J. \& KORNELIUS, J. Linguistische Probleme der Übersetzung. Tübingen, 1978.

FODOR, J.A. The Modularity of Mind. Cambridge, Mass, 1983.

GRICE, H.P. Logic and Conversation In: COLE, P. and MORGAN, J. (eds) Syntax and semantics 3: Speecb acts. New York, 1975, p.41-58.

GUTT, E-A. Translation and Relevance. London, 1991.

HÖNIG, H.G. \& KUßMAUL, P. Strategie der Übersetzung. Ein Lebr-und Arbeitsbuch. Tübingen, 1982.

HOUSE, J. A Model for Translation Quality Assessment. Tübingen, 1977.

KEIL, F.C. On Being More than the Sum of the Parts: The Conceptual Coherence of Cognitive Science. In: Psycbological Science 2/5, 1991, p.283/287-293.

KÖNIGS, F.G. Zentrale Begriffe aus der wissenschaftlichen Beschäftigung mit Übersetzen. In: Lebende Sprachen 4, Part 1, 1982, p.145-150; Lebende Sprachen 1, Part 2, 1983, p.6-8,48; Lebende Spracben 4, Part 3, 1983, p.154-56; Lebende Spracben 2, Part 4, pp.57-59; Lebende Spracben 4, Pant 5, 1984, p.153-56.

. Was beim Übersetzen passiert. Theoretische Aspekte, empirische Befunde und praktische Konsequenzen. In: Die Neueren Spracben 2, 1987, p.162185.

. Wie theoretisch muß die Übersetzungswissenschaft sein? Gedanken zum Theorie-Praxis-Problem. In: Taller de Letras 18, 1990, p.103-120.

KRINGS, H.P. Was in den Köpfen von Ubersetzern vorgebt, Eine empiriscbe Untersucbung zur Struktur des Übersetzungsprozesses an fortgeschritenen Französischlernern. Tübingen, 1986.

LÖRSCHER, W. Modelle des Übersetzungsprozesses: Anspruch und Wirklichkeit. In: Fremdspracben lebren und lernen 17, 1988, p.62-83.

Translation Performance, Translation Process and Translation Strategies. A Psycholinguistic Investigation. Tübingen, 1991.

MATURANA, H.R. \& VARELA, F.J. The Tree of Knowledge. Boston/London, 1988.

NEUBER'T, A. Thesen zur Translationstheorie und zu Problemen ihrer Anwendung in der Translationsdidaktik. In: HOLZ-MÄNTTÄRI, J. Translationstheorie Grundlage und Standorte. Tampere, 1988. 
NEWMARK, P. Approaches to Translation. Oxford, 1981.

. A Textbook of Translation. New York, 1988.

NIDA, E.A. Towards a Science of Translation: with special reference to the principles and procedures involved in bible translating. Leiden, 1964.

- Language Structure and Translation. Stanford, 1975.

NORD, C. Textanalyse und Übersetzen. Theoretiscbe Grundlagen, Metbode und didaktiscbe Anwendung einer übersetzungsrelevanten Textanalyse. Heidelberg, 1988.

POSNER, M.I. Foundations of Cognitive Science. Cambridge, 1989.

REIß, K. \& VERMEER, H.J., Grundlegung einer allgemeinen Translationstbeorie. Tübingen, 1984.

SEARLE, J.R. Consciousness, Explanatory Inversion, and Cognitive Science. In: Bebavioral and Brain Sciences 13/3, 1990, p.585-596. . The Rediscovery of the Mind. London, 1992.

SÉGUINOT, C. The Translation Process. London, 1989.

SHANNON, C. \& WEAVER, W. The mathematical Theory of Communication. Urbana, 1949.

SNELL-HORNBY, M., Translation Studies. An Integrated Approach. Amsterdam/ Philadelphia, 1988.

SPERBER, D. and WILSON, D. Relevance: Communication and Cognition. Oxford, 1986.

THIEL,G. Überlegungen zur übersetzungsrelevanten Textanalyse. In: WILSS, Übersetzungswissenschaft, 1981, p.367-383.

TRUFFAUT, L. Problèmes linguistiques de traduction allemand-français. Guide de l'étudiant et du practicien. Munique, 1983

VARELA, F.J., THOMPSON, E. \& ROSCH, E. The Embodied Mind. London, 1991.

VINAY, J.P. \& DARBELNET, J., Stylistique Comparée du francais et de l'anglais: Métbode de traduction. Paris, 1958.

WILSS, W. Kognition und Übersetzen. Zur theorie und Praxis der menscblichen und mascbinellen Übersetzung. Tübingen, 1988. 